\title{
Modelling the effects of ice transport and sediment sources on the form of detrital thermochronological age probability distributions from glacial settings
}

Maxime Bernard et al.

Correspondence to: Maxime Bernard (mabernard.ns@gmail.com)

The copyright of individual parts of the supplement might differ from the CC BY 4.0 License. 


\section{Complementary figures for the main text}

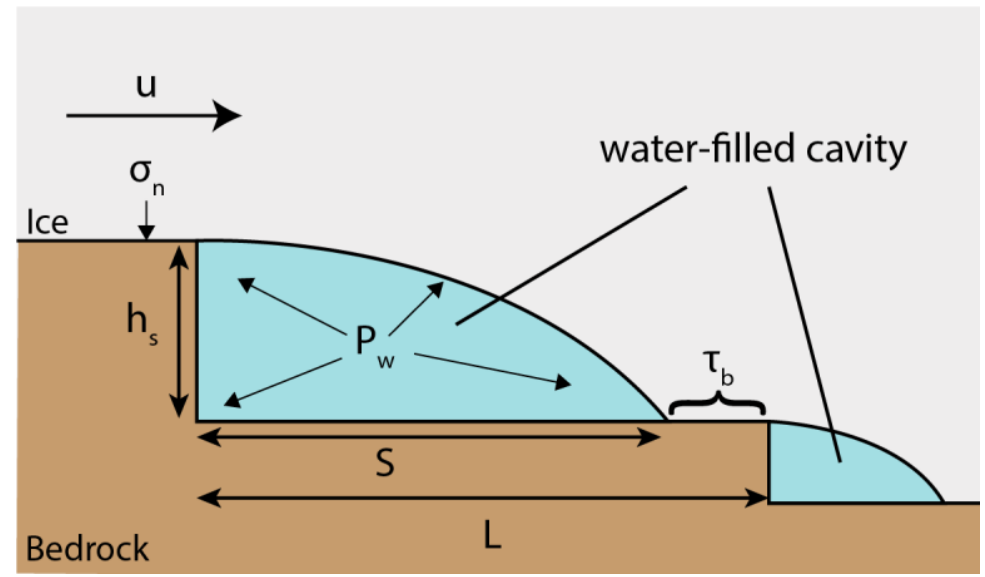

Figure S1: Flowing of ice over two bed steps. The geometry of cavities is defined by the height of the bed step ( $\left.h_{s}\right)$ and their length $(S)$. $L$ is the distance between two bed steps. The ice exerts normal pressure $\left(\sigma_{n}\right)$ on the bed, where the ice-bed contact length is defined by $\mathrm{L}-\mathrm{S}$. The basal shear stress $\left(\tau_{\mathrm{b}}\right)$ is applied on this length. $\mathrm{P}_{\mathrm{w}}$ is the water pressure within a cavity, (see text of Sect. 2.1). Modified after Iverson (2012).

Table S1. Range of parameters values used to calibrate the iSOSIA model for the Tiedemann glacier with the results of the ITMIX experiments, see Fig. S3.

\begin{tabular}{|lll|}
\hline \multicolumn{1}{|c}{ Tested parameters } & \multicolumn{1}{c}{ Description } & \multicolumn{1}{c|}{ Model parameters value } \\
\hline $\mathrm{Cs}$ & Ice sliding constant & $1 \times 10^{-2}-3 \times 10^{-2} \mathrm{~Pa} \mathrm{~s}^{1 / 3}$ \\
$\mathrm{dTa}$ & Annual temperature variation amplitude & $4-6^{\circ} \mathrm{C} \mathrm{km}^{-1}$ \\
$\mathrm{M}_{\mathrm{acc}}$ & Maximum accumulation rate & $2-5 \mathrm{~m} \mathrm{yr}^{-1}$ \\
$\mathrm{k}_{0}$ & Minimum hydraulic conductivity & $1 \times 10^{-5}-1 \times 10^{-3} \mathrm{~kg}^{-1 / 2} \mathrm{~m}^{3 / 2}$ \\
\hline
\end{tabular}

In the Table S1, the annual temperature variation amplitude (dTa) is used to calculate the annually averaged mass balance gradient in iSOSIA:

$$
\dot{M}_{b}=\dot{A}-\dot{M},
$$

where $\dot{M}_{b}$ is the mass balance gradient, $\dot{A}$ the accumulation and $\dot{M}$ the melting rates. The two last parameters are computed according to the number of positive temperature degree days $\left(N_{P D D}\right)$ :

$$
\begin{gathered}
\dot{M}=\dot{M}_{P D D} * N_{P D D} \\
\dot{A}=\frac{N_{F d}}{n},
\end{gathered}
$$

where $\dot{M}_{P D D}=10^{-3}$ is the positive degree day melt rate constant, $N_{F d}$ the number of frost days ( $\mathrm{T}<$ $0^{\circ} \mathrm{C}$ ) and $\mathrm{n}=365$ days, the number of days in a year. To calculate the number of positive degree day in 
the year, we use a sinusoidal variation for the temperature $(T)$ to represent the temperature variation with seasons:

$$
T=T_{0}+d T a \cdot \sin \left(\frac{2 \pi t}{n}\right),
$$

where $T_{0}$ is a temperature vector for the range of temperature amplitude variation (i.e. from - $2 \mathrm{dTa}$ to $+2 \mathrm{dTa})$, and $\mathrm{t}$ the time in days.

(a)

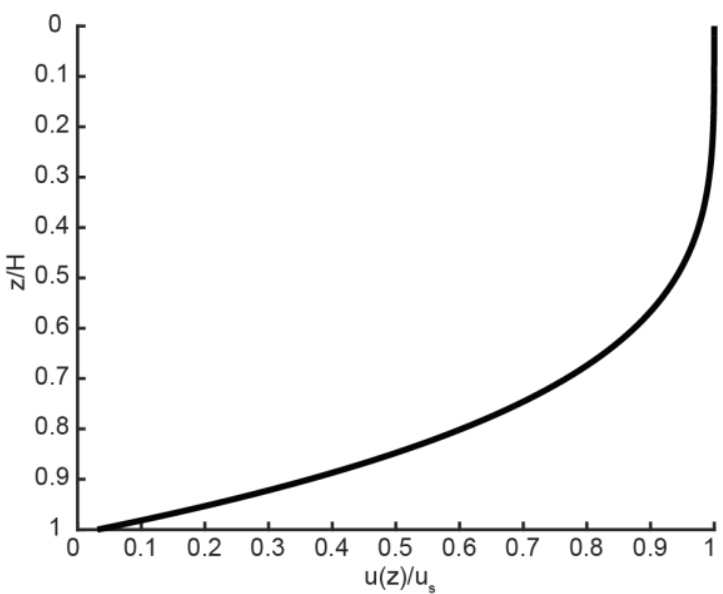

(b)

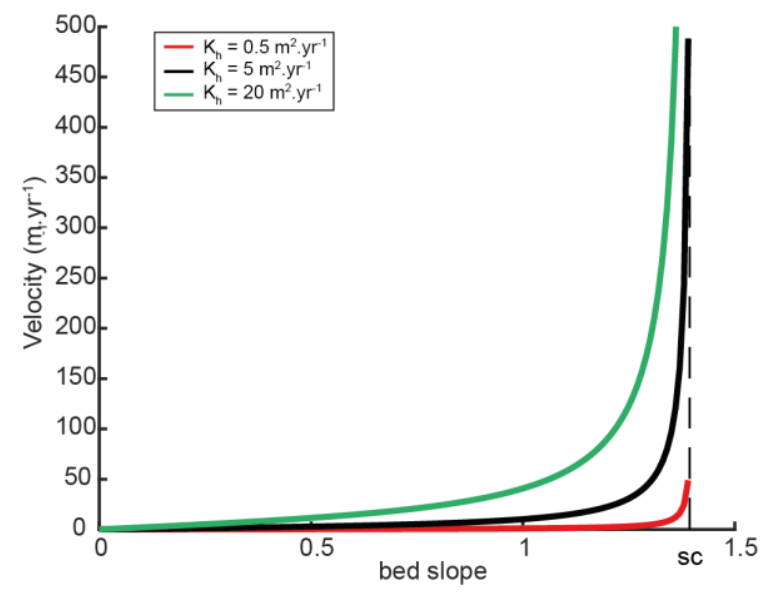

Figure S2: Velocity distribution for the glaciated particles (a) and particles located on hillslopes (b), $\mathrm{s}_{\mathrm{c}}$ is the critical slope. The parameters $\mathrm{z}$ and $\mathrm{H}$ are the vertical position of a particle in the ice and the ice thickness, respectively. The velocity of glaciated particles is denoted as $u(z)$ and $u_{s}$ represents the ice surface velocity, (see text in Sect 2.2). The green and red curve in (b) are the hillslope velocity distributions used for model sensitivity tests (see section 2 in supplementary materials).
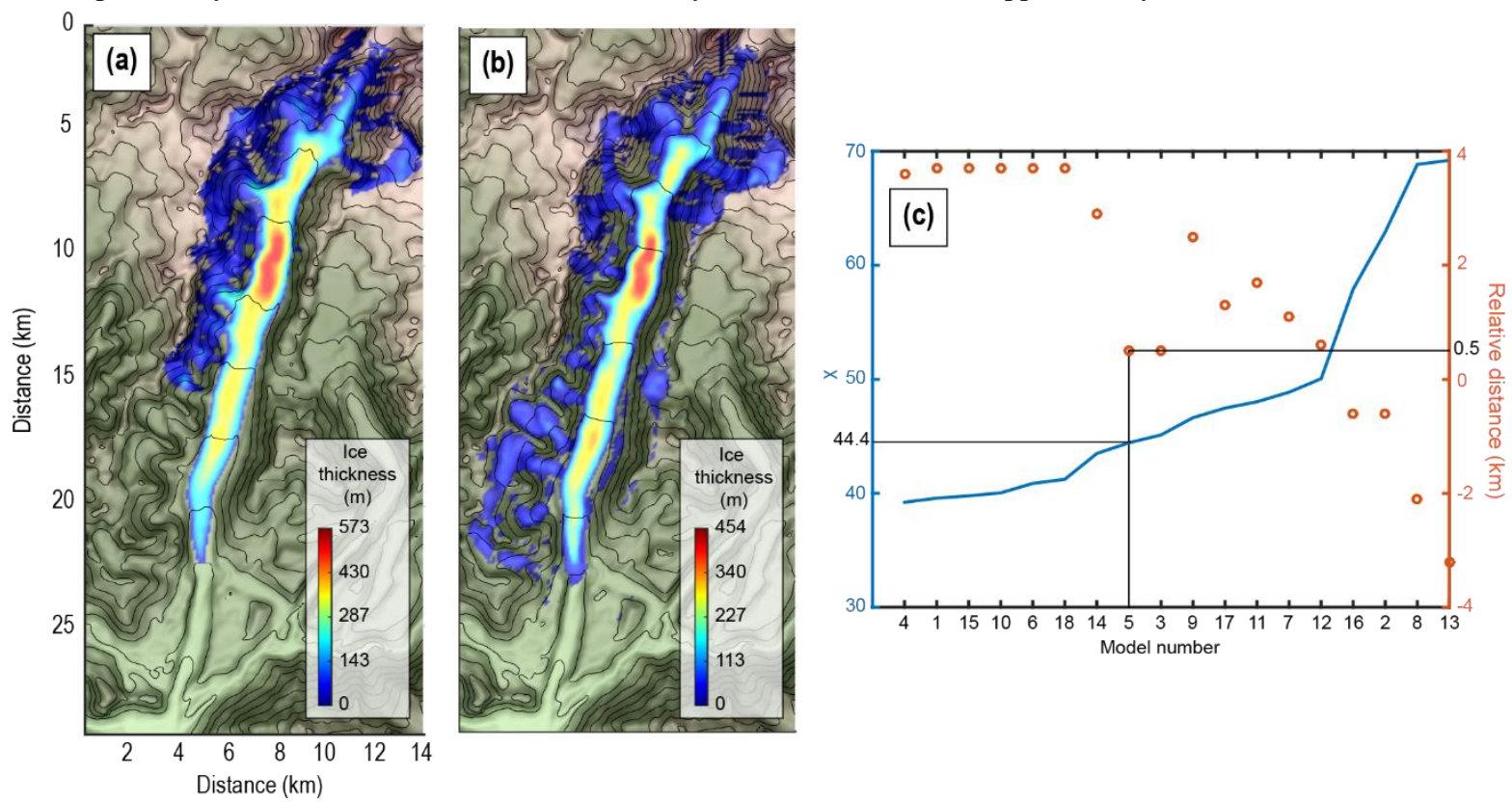

Figure S3: Calibration of the iSOSIA model for the Tiedemann glacier. (a) The ice thickness from the ITMIX experiments (Farinotti et al., 2016), (b) the ice thickness of the iSOSIA model, and (c) discriminating parameters used for the calibration of the iSOSIA model. The two parameters are the chi value of the mean ice thickness difference between the iSOSIA and ITMIX models (blue curve), and the relative position of the glacier front of the iSOSIA model with the ITMIX results (orange circles). We chose the iSOSIA model ${ }^{\circ} 5$ as it shows the best compromise between the mean ice thickness difference (chi value) and the position of the glacier front compare to the ITMIX experiments results (see text in Sect 2.3). 

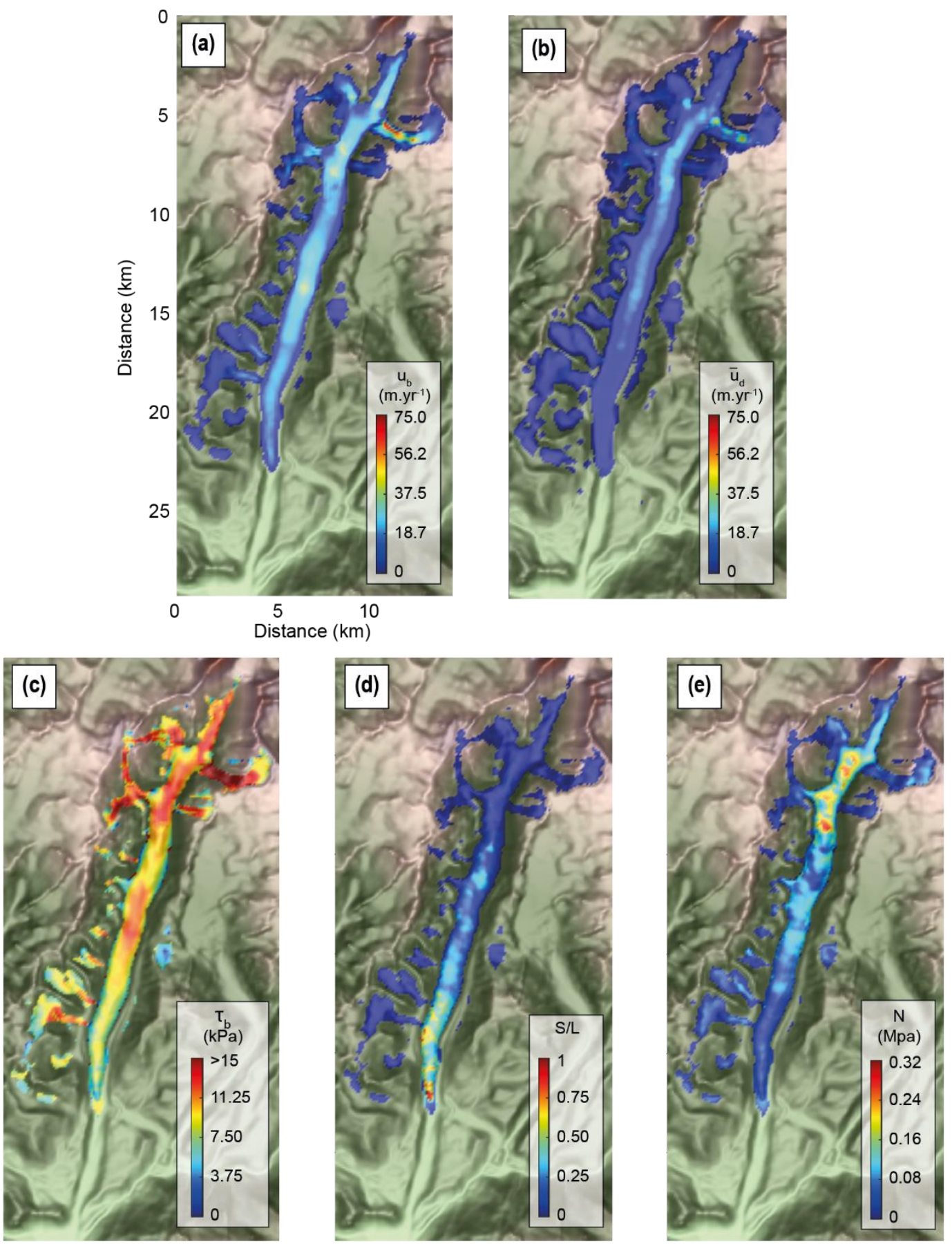

Figure S4: Spatial distribution of main outcomes for the modelled Tiedemann glacier. Spatial distribution of (a) the basal sliding speed, $\mathrm{ub}_{\mathrm{b}},(\mathrm{b})$ the ice deformation speed, $\bar{u}_{d}$, (c) the basal shear stress, $\tau_{\mathrm{b}}$, (d) the opening cavity ratio, $\frac{S}{L}$, and (e) the effective pressure, N. S and L are the size of cavities and bed steps wavelength, see Fig. (S1) (see text in Sect 2.3). 
(a)

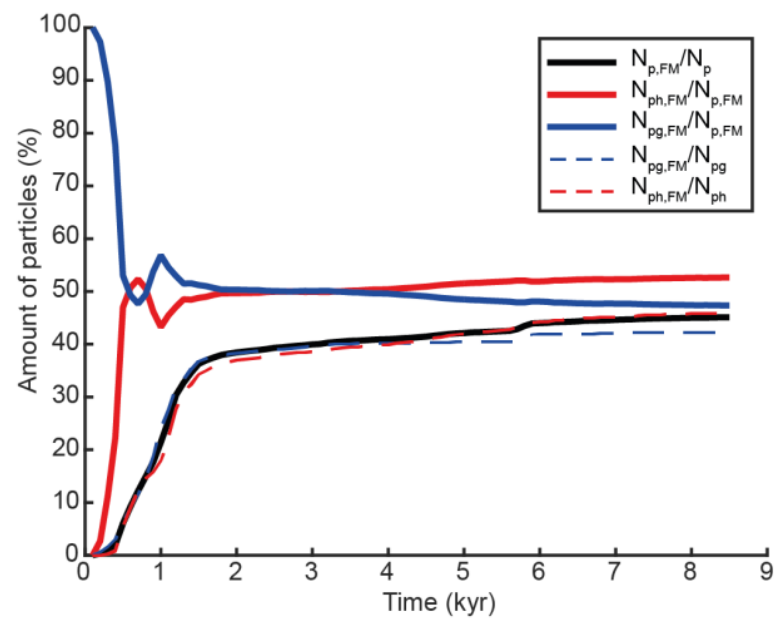

(b)

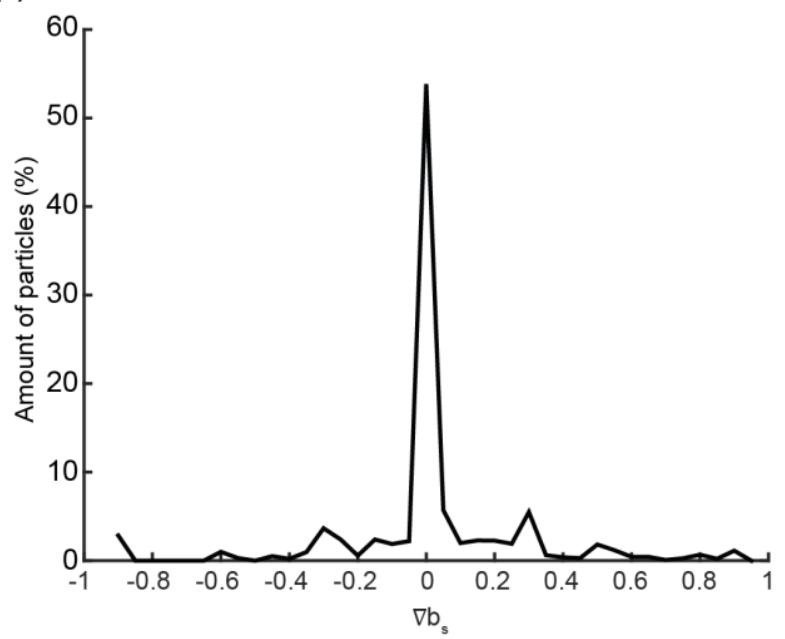

Figure S5: Kinematics of particle transport. (a) Transient evolution of the particle sources (hillslope vs glacial) in the frontal moraine. $\mathrm{N}_{\mathrm{p}}$ : total number of particles, $\mathrm{N}_{\mathrm{ph}}$ : total number of particle originated from hillslope, $\mathrm{N}_{\mathrm{pg}}$ : total number of particle originated from glaciers, $\mathrm{N}_{\mathrm{p}, \mathrm{FM}}$ : total number of particle in the Frontal Moraine (FM), $\mathrm{N}_{\mathrm{ph}, \mathrm{FM}}$ : number of hillslope-origin particle in the FM, and $\mathrm{N}_{\mathrm{pg}, \mathrm{FM}}$ : number of glacier-origin particles in the FM. (b) Distribution of the bed slope in direction of sliding for tributary glacier carrying glaciated particles that remain close to their source after 8500 years of simulation. (See text in Sect 3.2)
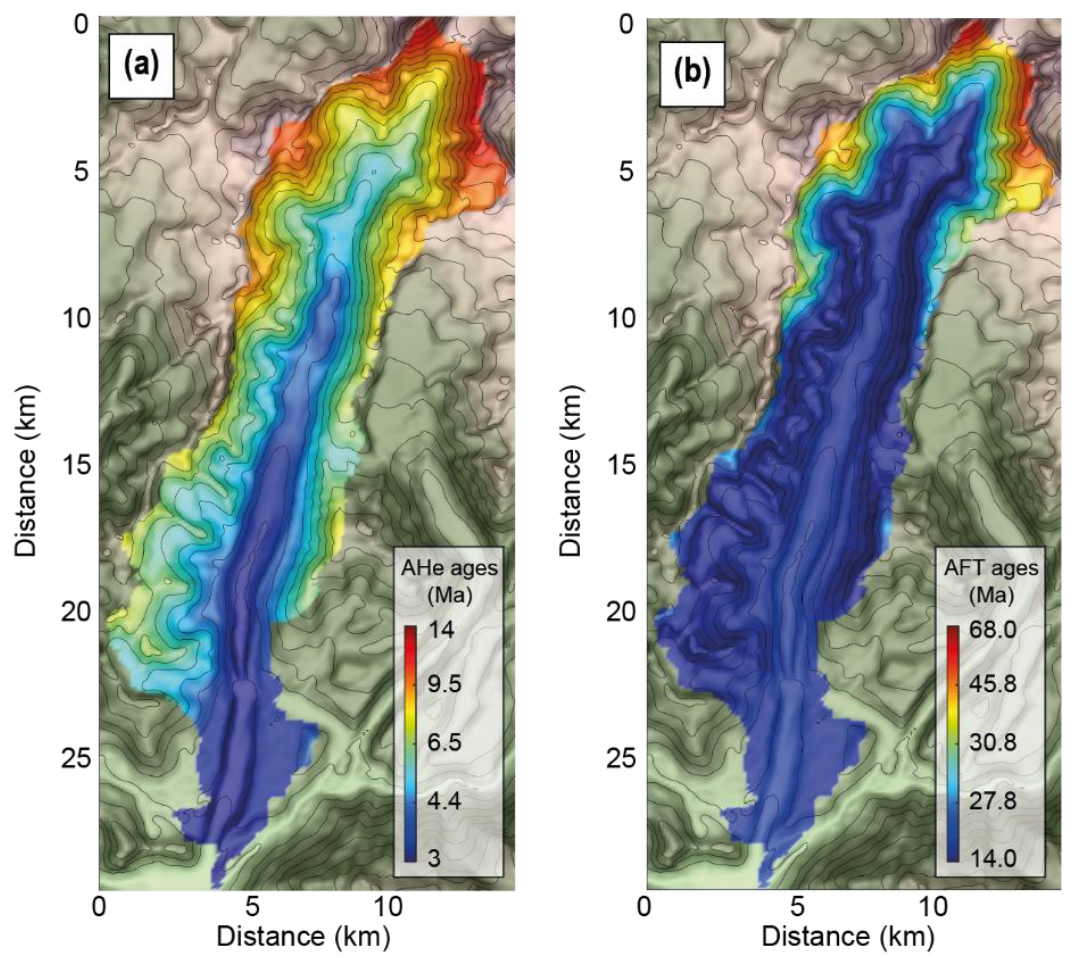

Figure S6: Spatial bedrock age distributions for the (a) AHe and (b) AFT systems. (See text in Sect 3.2) 

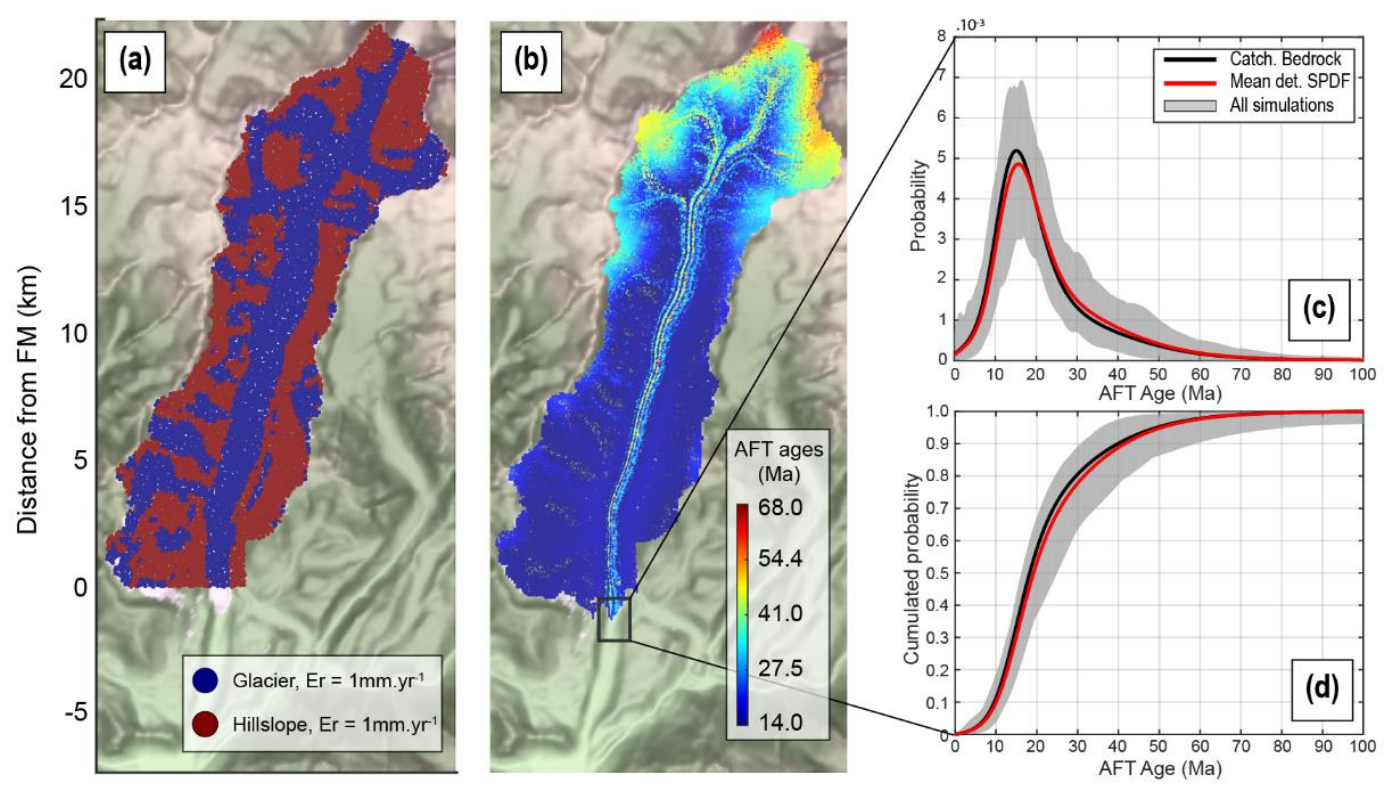

Figure S7: Spatial distribution of particles and detrital AFT age distributions within the frontal moraine. (a) Source locations of particles, with Er being the erosion rate. The spatial AFT age distributions after $2000 \mathrm{yrs}$ of particles transport (b). The AFT age probability distributions (c) and their cumulative values (d). The grey shaded area represents the range of the inferred 10,000 detrital SPDFs from the sampling process. The black square in (b) shows the frontal moraine (FM) position. (See text in Sect 3.3 and 3.4)
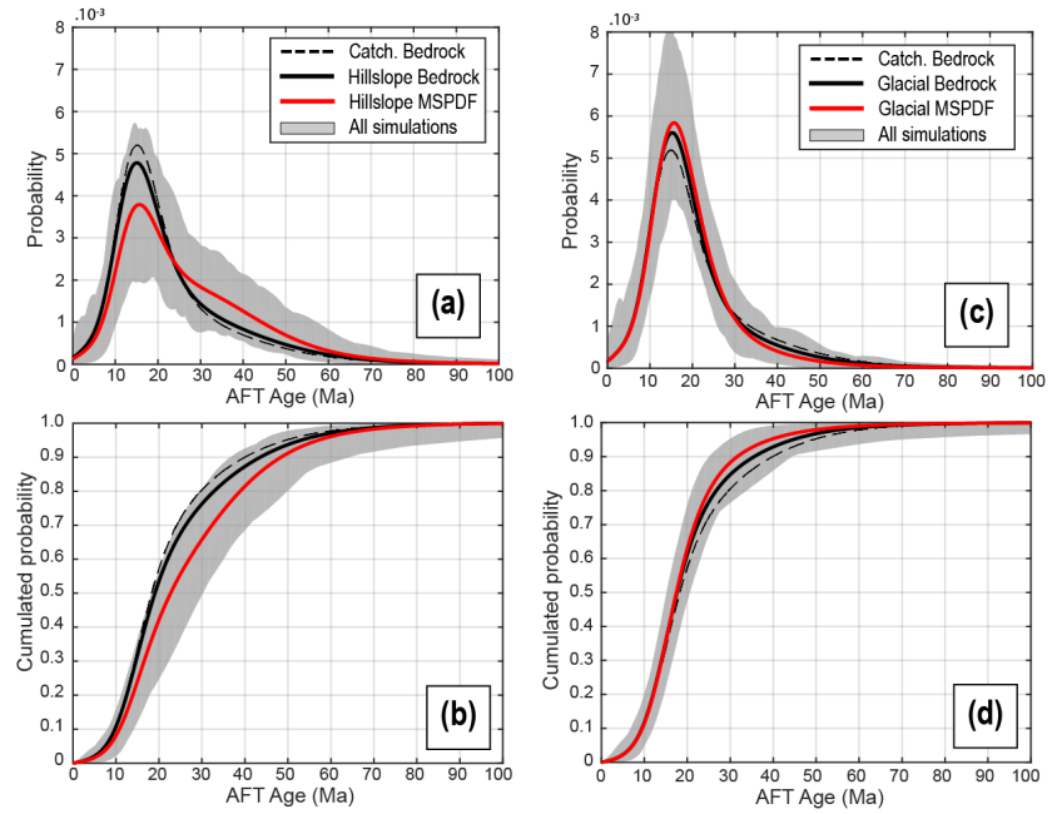

Figure S8. AFT detrital age and cumulated distributions of the frontal moraine, for models considering only ice-free hillslope sources (a-b) and glacial sources (c-d). The grey shaded area represents the range of the inferred 10,000 detrital SPDFs from the sampling process MSPDF: Mean Synoptic Probability Distribution. 

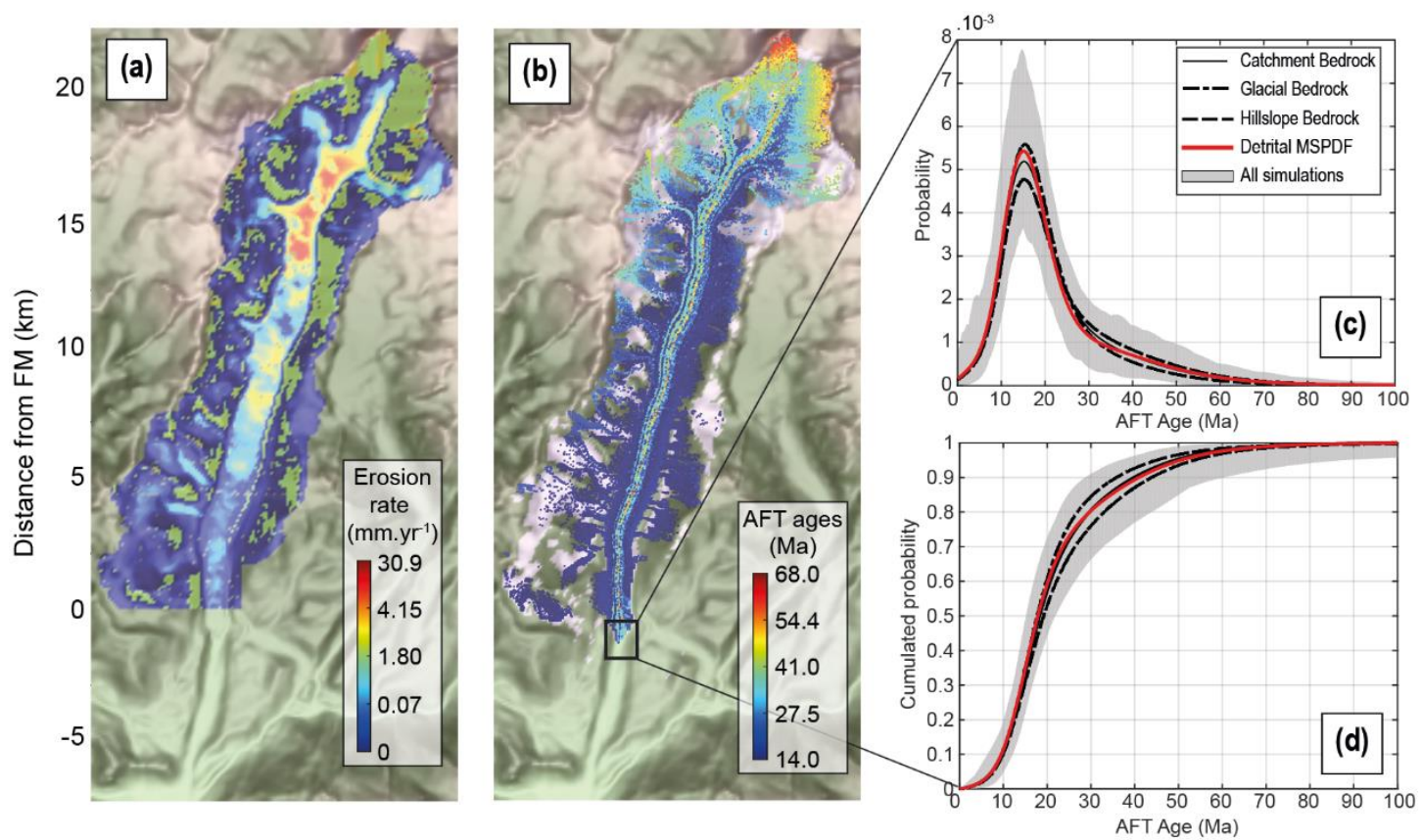

Figure S9: Non-uniform erosion model experiment, with (a) the erosion rate, (b) the spatial AFT age distribution of particles after 2 kyrs of transport, (c) the AFT age probability distributions and (d) their cumulative values for the frontal moraine. The grey shaded area represents the range of the inferred 10,000 detrital SPDFs from the sampling process. The black square in (b) shows the frontal moraine (FM) location (See text in Sect. 3.5). MSPDF: Mean Synoptic Probability Density Function.
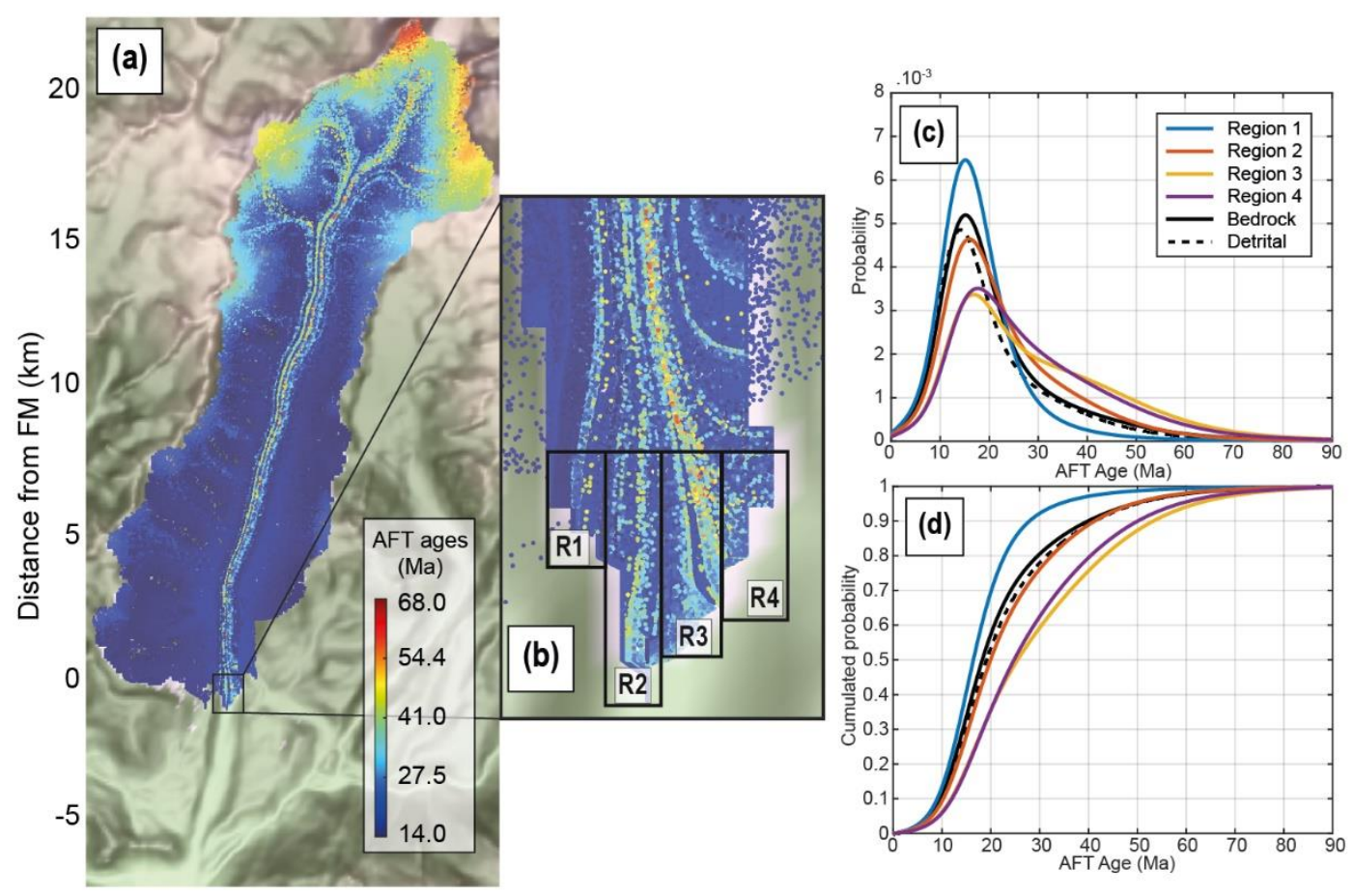

Figure S10: Detrital AFT age distribution of the four regions seen in (b, black squares) from the experiment considering uniform source of particle. Spatial distribution of particles with their AFT ages associated (a), with a zoom to the frontal moraine area in (b). The density plots and their cumulated distribution are shown in (c) and (d). The dashed black line is the mean detrital SPDF for the frontal moraine (FM). R: region (See text in Sect. 4.4). 


\section{Model sensitivity tests}

To test the sensitivity of our results, we performed four additional models with various parameters for ice, climate, and hillslopes. Two of them are testing the influence of the Tiedemann glacier size. We choose models 16 and 17 (Fig. S3), to perform such analyses as they show glacier front position $\sim 1000$ $\mathrm{m}$ farther and shorter than the model used in this study (the reference model). We are limiting to this glacier size range to keep an erosion area similar to the reference model (See Fig. 6a in the main text), that means, bounded by the reference frontal moraine (FM). These two models have different combinations of four parameters: Cs, the ice sliding constant; $\mathrm{dTa}$, the temperature amplitude for mass balance; $\mathrm{M}_{\mathrm{acc}}$ the maximum ice accumulation rate; and $\mathrm{k}_{0}$, the minimum hydraulic conductivity (Table S2). We stress that, because the size of the glacier changes for the models M16 and M17, we define our frontal moraine to be the last $800 \mathrm{~m}$ of each synthetic Tiedemann glacier (i.e. according to the frontal moraine of the reference model). The two other models (Hill1 and Hill3) test the influence of the hillslope diffusivity, $\mathrm{K}_{\mathrm{h}}$, for particles in:

$$
q_{p h}=-\frac{K_{h} \cdot \nabla b}{1-\left(\frac{|\nabla b|}{S_{c}}\right)^{2}},
$$

where $\nabla b$ is the bed slope and $\mathrm{s}_{\mathrm{c}}$ the critical slope. The resulting hillslope velocity profiles for particles of models Hill1 and Hill3 can be seen in Fig. S2.

Table S2. Values for variable parameters used for the model sensitivity tests. Empty boxes are values that do not change from the reference.

\begin{tabular}{|lccccc|}
\hline \multicolumn{1}{|c}{ Tested parameters } & M16 & M17 & Hill1 & Hill3 & Ref \\
\hline $\mathrm{Cs}\left(\mathrm{Pa} \mathrm{s}^{1 / 3}\right)$ & $2,06.10^{-2}$ & $2,39.10^{-2}$ & - & - & $1,29.10^{-2}$ \\
$\mathrm{dTa}\left({ }^{\circ} \mathrm{C} \mathrm{km}^{-1}\right)$ & - & 5 & - & - & 6 \\
$\mathrm{M}_{\mathrm{acc}}\left(\mathrm{m} \mathrm{yr}^{-1}\right)$ & 2,37 & 2,25 & - & - & 2,73 \\
$\mathrm{k}_{0}\left(\mathrm{~kg}^{-1 / 2} \mathrm{~m}^{3 / 2}\right)$ & $4,1.10^{-3}$ & $4,0.10^{-3}$ & - & - & $3,10.10^{-4}$ \\
$\mathrm{~K}_{\mathrm{h}}\left(\mathrm{m}^{2} \mathrm{yr}^{-1}\right)$ & - & - & 0.5 & 20 & 5 \\
\hline
\end{tabular}

First, we consider the evolution of the particle source proportion in the frontal moraine for these four models (Fig. S11). Looking at the models Hill1 and Hill3 (Fig. S11a-b), we see that the effect of the hillslope diffusivity is found at the first stages ( 0 to 3000 years) of the frontal moraine evolution. Indeed, the glacial sources are dominant over the hillslope sources (solid blue and red curves, Fig. S11) in the case where the diffusivity on hillslopes is small $\left(\mathrm{K}_{\mathrm{h}}=0.5 \mathrm{~m}^{2} \mathrm{yr}^{-1}\right)$. This is explained by the associated low velocity profile on hillslopes that increases the transfer times of such particles within the catchment (Fig. S2). Moreover, the time to reach equilibrium in the FM is increased for the lower diffusivity value (i.e. black curves), and is around 3-4 kyrs. However, after 8500 years of simulation, the total proportion of sources in the FM is similar for all models ( $~ 50 \%$, solid blue and red curves), as is the total proportion of initial particles that reaches the FM around 40-44\% (black curves, Fig. S11a-b). Consequently, the proportion of particles deposited outside the FM is still around 60-56 \%, for models considering variation in the hillslope diffusivity, $\mathrm{K}_{\mathrm{h}}$, and the reference model.

A similar analysis on the model M17 shows that the FM is always dominated by the glacial sources (solid blue curve, Fig. S11d) compared to the model M16 (Fig. 11c) and the reference model (Fig. 5a), where the dominance of a source varies with time. For the model M17, the glacier front is $1000 \mathrm{~m}$ farther than in the reference case and explain this discrepancy. Indeed, as glacier ice velocities are higher $(\sim 60$ $\mathrm{m} \mathrm{yr}^{-1}$ ) in the centreline (see Fig. 3c, main text), glaciated particles are moving faster than hillslopeorigin particles, and thus reach the FM first. The results for the model M16 (Fig S11c) show differences in the evolution of the particle sources proportion in the FM, as the hillslope source is dominating over 
the glacial source. At the end of simulation (8500 years) the proportion of particles coming from hillslopes is $\sim 57 \%$ and thus particles coming from the glacier $\sim 43 \%$. The total proportion of particles reaching the FM is $\sim 45 \%$. Overall, the proportion of the initial particles that reach the FM in each model, in the models M16 and M17, is similar to the reference ( 44\%). Thus, the proportion of initial particles that remains stored higher in the catchment is $\sim 56-50 \%$, consistent with the reference model.
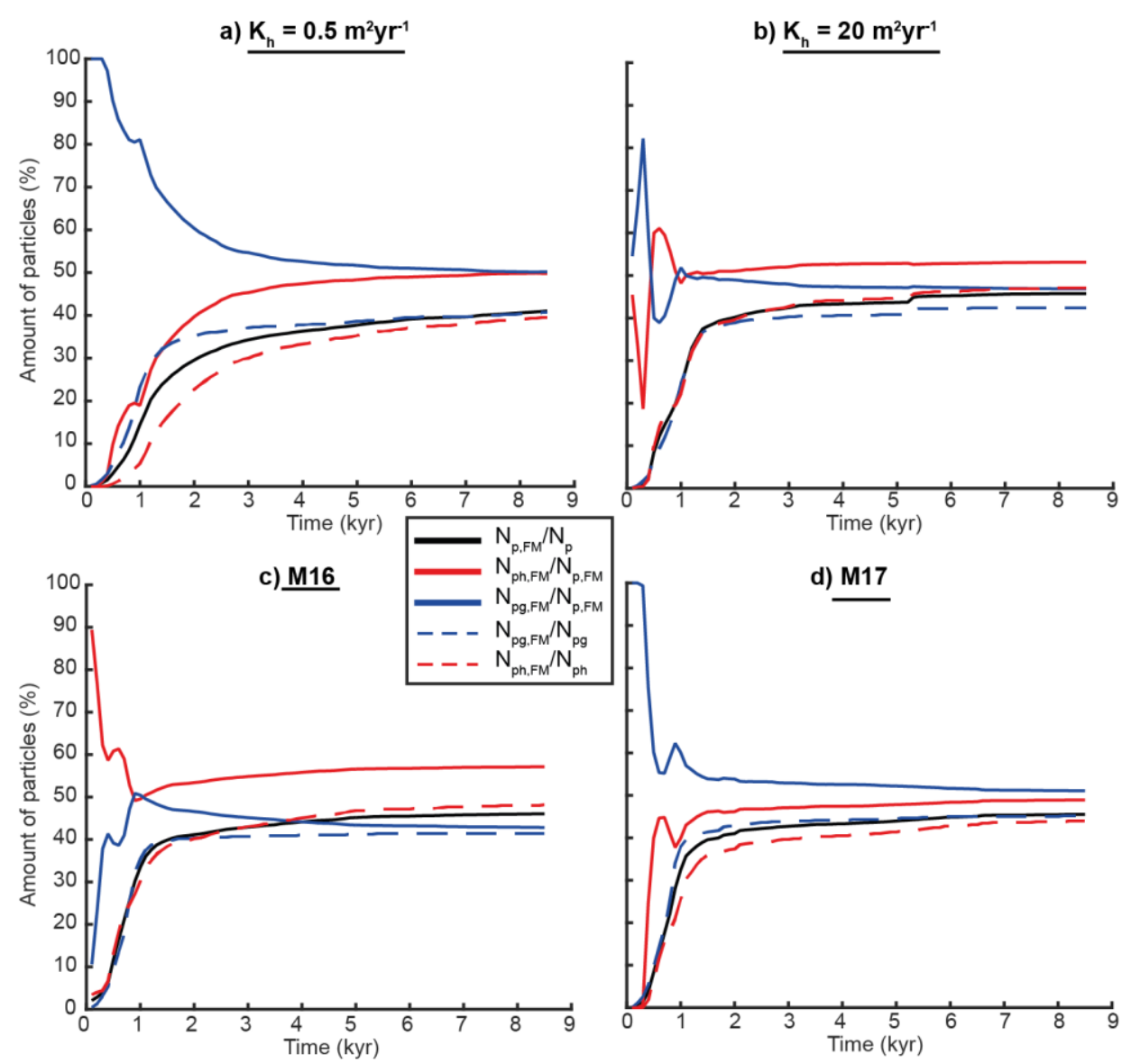

Figure S11: Transient evolution of the particle sources (hillslope vs glacial) in the frontal moraine, for model sensitivity tests: Hill1 (a), Hill3 (b), M16 (c), and M17 (d). $\mathrm{N}_{\mathrm{p}}$ : total number of particles, $\mathrm{N}_{\mathrm{ph}}$ : total number of particle originated from hillslope, $\mathrm{N}_{\mathrm{pg}}$ : total number of particle originated from glaciers, $\mathrm{N}_{\mathrm{p}, \mathrm{FM}}$ : total number of particle in the Frontal Moraine $(\mathrm{FM}), \mathrm{N}_{\mathrm{ph}, \mathrm{FM}}$ : number of hillslope-origin particle in the FM, and $\mathrm{N}_{\mathrm{pg}, \mathrm{FM}}$ : number of glacier-origin particles in the FM. The results from the reference model are presented in Fig. S5a.

We now analyse the detrital age distributions associated to the previous models after 8500 years of simulation. For all models we look at the mean detrital SPDFs of the two thermochronological systems (AHe and AFT) that result from sampling the frontal moraine (Fig. S12a-d). For the model sensitivity tests considering variation in the hillslopes diffusivity (Hill1 and Hill3), we see no significant differences with the reference (blue curve) for both AHe and AFT systems. For models M16 and M17, the differences are higher for the AHe system and less pronounced for the AFT system. The detrital SPDF of M17 (Fig S12c) under-represent younger ages, 3.3 and $\sim 4.3 \mathrm{Ma}$ (i.e. glacial sources) compared to the reference model, and integrates more ages $\sim 7$ Ma. The detrital SPDF of M16 better matches the reference detrital SPDF. 
AHe system

Hillslope sensitivity
(Fig. 6c-d, main text)

Ice sensitivity

(Fig. 6c-d, main text)
Hillslope sensitivity (Fig. 7c, main text, Fig. S7c)

Ice sensitivity

(Fig. 7c, main text, Fig. S7c)
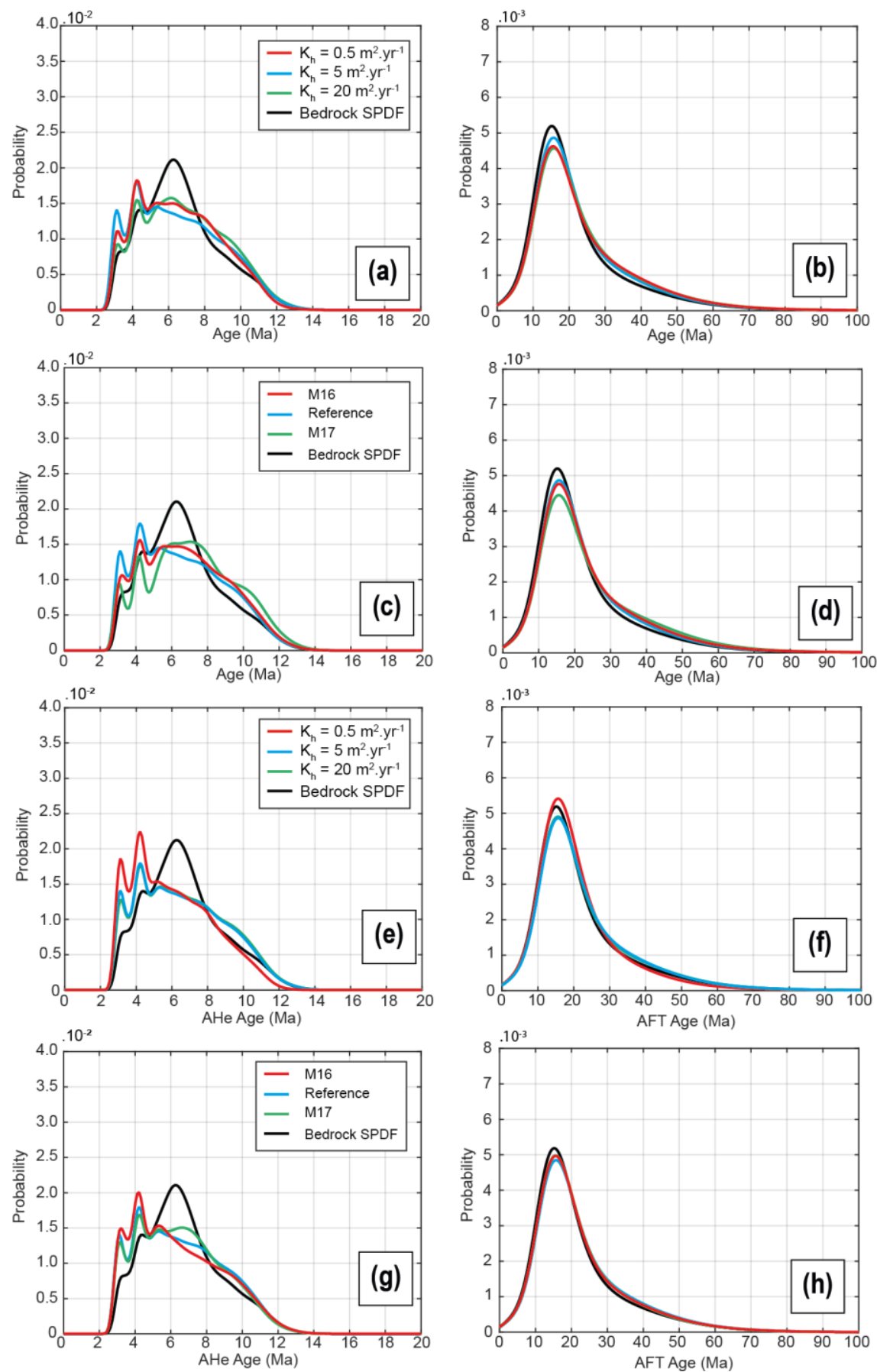
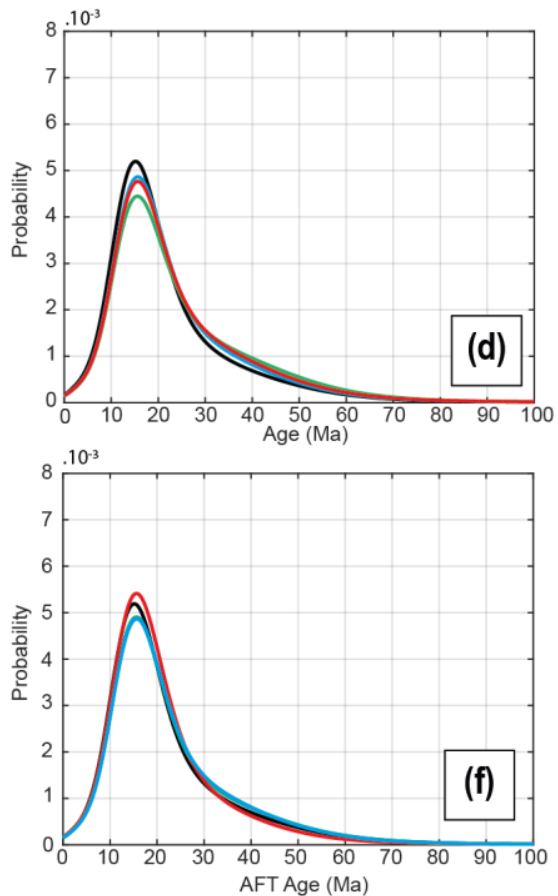

AFT system

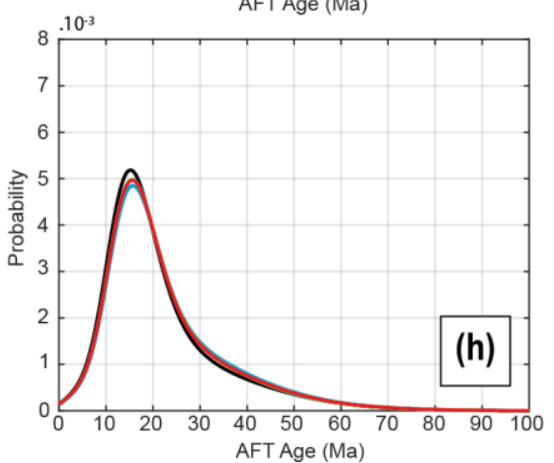

Figure S12: Mean detrital age distributions (SPDFs) from model sensitivity tests, for both the AHe and AFT thermochronological systems. From (a) to (d), the detrital SPDFs resulting from sensitivity model tests considering one pulse of particles production in each grid cell (see Sect. 3.1 for more details). From (e) to (h), sensitivity model tests considering continuous production of particles (see Sect. 3.2 for more details).

Similar comparisons can be made for the detrital SPDFs resulting from models considering continuous uniform production of particles (Fig. S12e-h). The AHe detrital SPDF from the model sensitivity tests with low hillslope diffusivity $\left(\mathrm{K}_{\mathrm{h}}=0.5 \mathrm{~m}^{2} \mathrm{yr}^{-1}\right)$, over-represents younger ages compared to the reference as the transfer times of hillslope-origin particles are increased. The same is observed for the AFT system. Increasing the hillslope diffusivity $\left(\mathrm{K}_{\mathrm{h}}=20 \mathrm{~m}^{2} \mathrm{yr}^{-1}\right)$, compared to the reference model, does not change the results as the detrital SPDF is equivalent to the reference (Fig S12e-f). This suggests that maximum transfer times on hillslopes are already reached at least in the reference model that considers value for 
hillslope diffusivity equal to $5 \mathrm{~m}^{2} \mathrm{yr}^{-1}$. Finally, the resulting AHe detrital SPDFs for models M16 and M17 show higher proportion of younger ages ( $\sim 3.3$ and $\sim 4.3$ Ma, Fig. 12g-h) than the previous case (Fig. S12c-d). This is because of the continuous production of sediment particles, where the lower transfer times of the particles coming from the glacier source act to increase the proportion of younger ages that reach the moraine over time.

Despite the change in glacier size $( \pm 1000 \mathrm{~m})$, the results from the models M16 and M17 show low variations in the resulting detrital age distributions compared to the reference. In fact, this change in size has had small impact on the distribution of ice velocities (Fig. S13). Thus, the kinematic of particles is overall similar to the reference.

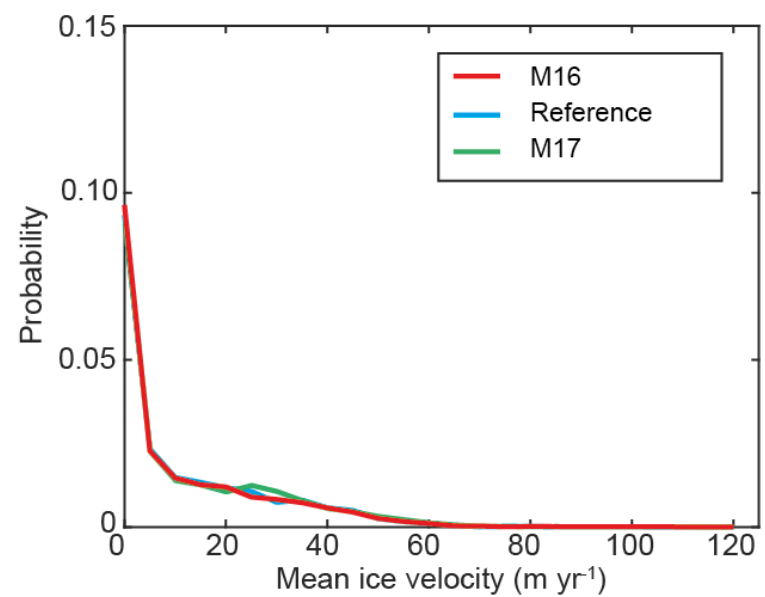

Figure S13: Comparison of the ice velocity distribution across the modelled Tiedemann glacier, for sensitivity model tests M16, M17, and the reference.

\section{References}

Farinotti, D., Brinkerhoff, D., Clarke, G. K., Fürst, J. J., Frey, H., Gantayat, P., ... and Linsbauer, A.: How accurate are estimates of glacier ice thickness? Results from ITMIX, the Ice Thickness Models Intercomparison eXperiment. The Cryosphere Discussions, https://doi.org/10.5194/tc-2016-250, 2016.

Iverson, N. R.: A theory of glacial quarrying for landscape evolution models. Geology, 40(8), 679-682, https://doi.org/10.1130/G33079.1, 2012. 
